\title{
Shear Tests for Ultra-High Performance Fiber Reinforced Concrete (UHPFRC) Beams with Shear Reinforcement
}

\author{
Woo-Young Lim ${ }^{1)}$, and Sung-Gul Hong ${ }^{2), *}$
}

(Received March 17, 2016, Accepted April 26, 2016, Published online May 26, 2016)

\begin{abstract}
One of the primary concerns about the design aspects is that how to deal with the shear reinforcement in the ultra-high performance fiber reinforced concrete (UHPFRC) beam. This study aims to investigate the shear behavior of UHPFRC rectangular cross sectional beams with fiber volume fraction of $1.5 \%$ considering a spacing of shear reinforcement. Shear tests for simply supported UHPFRC beams were performed. Test results showed that the steel fibers substantially improved of the shear resistance of the UHPFRC beams. Also, shear reinforcement had a synergetic effect on enhancement of ductility. Even though the spacing of shear reinforcement exceeds the spacing limit recommended by current design codes (ACI 318-14), shear strength of UHPFRC beam was noticeably greater than current design codes. Therefore, the spacing limit of $0.75 d$ can be allowed for UHPFRC beams.
\end{abstract}

Keywords: spacing limit, shear reinforcement, ultra-high performance fiber-reinforced concrete (UHPFRC), shear strength, shear test, failure modes.

\section{Introduction}

Recently, the steel fiber-reinforced concrete (SFRC) has been widely used as structural material due to its remarkable mechanical properties compared to conventional concrete. Through the numerous experimental studies, it turns out that the addition of steel fibers can improve the structural capability of concrete (Fanella and Naaman 1985; Sharma 1986; Narayanan and Darwish 1987; Wafa and Ashour 1992; Ashour et al. 1992; Ezeldin and Balaguru 1997; Kwak et al. 2002). Even though SFRC has many advantages as structural material, some limitations still exist in the construction of the large-scale structures that requires very high compressive and tensile strength.

To overcome these limitations, ultra-high performance fiber-reinforced concrete (UHPFRC) has been developed. The UHPFRC has a compressive strength of about 150-200 MPa and a tensile strength of $10 \mathrm{MPa}$ or more (Rossi et al. 2005; Farhat et al. 2007; Wille et al. 2011a, b; Park et al. 2012). In addition, shear resistance of UHPFRC beam is outstanding. Previous research on shear tests for UHPFRC beam has focused on the I-shaped beam or girder without shear reinforcement because UHPFRC can reduce a web thickness of the beam due to its great compressive and tensile strength.

\footnotetext{
${ }^{1)}$ Institute of Engineering Research, Seoul National University, Seoul 08826, Korea.

${ }^{2)}$ Department of Architecture and Architectural Engineering, Seoul National University, Seoul 08826, Korea.

*Corresponding Author; E-mail: sglhong@snu.ac.kr Copyright ( $\odot$ The Author(s) 2016. This article is published with open access at Springerlink.com
}

According to Baby et al. (2014), the presence of shear reinforcement has increased the shear capacity of the beams. Voo et al. (2010) found that a significant distribution of shear cracking occurs prior to the formation of the critical failure crack. Due to its superior mechanical properties, the UHPFRC has been successfully applied in the construction of bridges and also used for retrofitting and strengthening existing concrete structures in building structures (Alaee and Karihaloo 2003; Meda et al. 2014).

One of the primary concerns about the design aspects is that how to deal with the shear reinforcement in the UHPFRC beams. The formation of inclined shear cracking might lead directly to critical failure without warning. To avoid sudden failure in beams, shear reinforcement is required in a proper spacing so that the shear reinforcement should intersect with the diagonal shear cracks, even when shear reinforcement is not necessary according to the computation. Current design codes for reinforced concrete (RC) beams (ACI 318-14 2015; EC2 2004; CSA A23.3-04 2004; AASHTO-LRFD 2004; MC2010 2012) requires a minimum shear reinforcement in beams to ensure adequate reserve shear strength and to prevent possible sudden shear failure, when the factored shear force $\left(V_{u}\right)$ exceeds $0.5 \phi V_{c}$. Here, $\phi$ is the strength reduction factor for shear and $V_{c}$ is the shear strength provided by concrete. Also, a spacing limit of shear reinforcement is served in design codes (ACI 318-14 2014; CSA A23.3-04 2004).

For SFRC beams, ACI 544 (1988) reported that the steel fibers show potential advantages as shear reinforcement. Previous studies have identified the synergetic effect of fiber volume fraction and presence of shear reinforcement on shear behavior of beams (Mansur et al. 1986; Narayanan 1987; Li et al. 1992; Khuntia et al. 1999; Noghabai 2000). 
They found that the combination of steel fibers and shear reinforcement depicted slow and controlled cracking and better distribution of tensile cracks, and minimized the penetration of shear cracks into the compression zone. According to Parra-Montesinos (2006), SFRC beams that contained fiber volume fraction $\left(V_{f}\right)$ more than $0.75 \%$ exhibited a shear stress at failure greater than the conservative lower bound value of $0.3 \sqrt{ } f_{c}^{\prime}$. Also, the use of a minimum $V_{f}$ of $0.75 \%$ has been recommended by ACI Subcommittee 318-F.

However, the effect of shear reinforcement in a rectangular UHPFRC beam section has not been recognized even though the design shear strength for the UHPFRC structural member is obtained by summing the shear strengths provided by cement matrix, steel fibers, and shear reinforcement (JSCE 2004; K-UHPC 2012; AGFC 2013). Especially, a spacing limit of shear reinforcement have not been provided due to the lack of previous test data. Thus, it is necessary to investigate the shear behaviour of the UHPFRC beams regarding the spacing of shear reinforcement because the rectangular beam section in building structures might require sufficient beam width to provide the shear reinforcement.

In this study, shear tests for simply supported rectangular UHPFRC beam sections with and without shear reinforcement were performed to characterize the shear behavior depending on the spacing of shear reinforcement. Also, the shear contribution for the spacing of shear reinforcement is discussed.

\section{Current Design Guidelines for Shear}

\subsection{Shear Strength}

The JSCE (2004) and K-UHPC (2012) design guidelines provide the shear strength of UHPFRC beam with or without shear reinforcement.

The design shear strength $\left(V_{d}\right)$ is obtained by summation of the shear strength provided by cement matrix, steel fiber, and shear reinforcement as follows:

$$
V_{d}=V_{c}+V_{f b}+V_{s}
$$

where $V_{c}, V_{f b}$, and $V_{s}$ are shear strength provided by cement matrix, steel fibers, and shear reinforcement, respectively.

The shear strength provided by cement matrix is obtained as given:

$$
V_{c}=\phi_{b} 0.18 \sqrt{f_{c}^{\prime}} b_{w} d
$$

where $\phi_{b}$ is the member reduction factor and is recommended as $0.77, f_{c}^{\prime}$ is the compressive strength, $b_{w}$ is the beam width, and $d$ is the effective depth of the beam.

The shear strength by steel fibers can be determined as follows:

$$
V_{f b}=\phi_{b}\left(\frac{f_{v d}}{\tan \beta_{u}}\right) b_{w} z
$$

where $f_{v d}$ is the design average tensile strength in the direction perpendicular to diagonal tensile crack; $\beta_{u}$ is the angle occurring between axial direction and diagonal tensile crack plane. This angle shall be larger than $30^{\circ}$. The value of $z$ is distance from the position of the resultant of the compressive stresses to the centroid of tensile steel (mm), generally $d / 1.15$.

In these guidelines, the design average tensile strength in the direction perpendicular to diagonal tensile crack can be expressed as Eq. (4) since the material reduction factor considers the orientation of the steel fibers. Thus, the value of $f_{v d}$ is obtained as follows:

$$
f_{v d}=\frac{1}{w_{v}} \int_{0}^{w_{v}} \phi_{c} \sigma_{k}(w) d w=\frac{1}{w_{v}} \int_{0}^{w_{v}} \sigma_{d}(w) d w
$$

where $w_{v}=\max \left(w_{u}, 0.3 \mathrm{~mm}\right) ; w_{u}$ is the ultimate crack width corresponding to peak stress on the outer fiber; $\phi_{c}$ is material reduction factor $(=0.8) ; \sigma_{k}(w)$ is the tension softening curve; and $\sigma_{d}(w)$ is equal to $\phi_{c} \sigma_{k}(w)$.

Shear strength by the shear reinforcement is provided in K-UHPC recommendations (2012) and it can be determined as follows:

$$
V_{s}=\phi_{b} \frac{A_{v} f_{y t}\left(\sin \alpha_{s}+\cos \alpha_{s}\right)}{s} d
$$

where $A_{v}$ is the cross sectional area of shear reinforcement; $f_{y t}$ is the design yield strength of shear reinforcement; $\alpha_{s}$ is the angle between longitudinal axis of beam and shear reinforcement; and $s$ is the spacing of shear reinforcement. It should be noted that JSCE guidelines does not provide this term.

In AFGC design guidelines (2013), shear strength of UHPFRC members is computed by summing $\left(V_{d}=V_{c}+V_{f b}+V_{s}\right)$ of the shear strength provided by cement matrices; steel fibers; and shear reinforcements in the same manner as other design recommendations assuming the web shear failure.

For a reinforced section, the term of shear strength provided by cement matrices is given by:

$$
V_{c}=\frac{0.21}{\gamma_{c f} \gamma_{E}} k \sqrt{f_{c}^{\prime}} b_{w} d
$$

where $\gamma_{c f}$ is the partial safety factor on fibers and is assumed to be a value of $1.3 ; \gamma_{E}$ is a safety coefficient; $\gamma_{c f} \gamma_{E}$ is equal to $1.5, k$ is determined by $1+3 \sigma_{c p} / f_{c}^{\prime}$ for $\sigma_{c p} \geq 0$; and $1+0.7$ $\sigma_{c p} / f_{c c, 0.05}^{\prime}$ for $\sigma_{c p}<0 ; \sigma_{c p}$ is calculated by the equation of $N_{e d} / A_{c} ; N_{e d}$ is the axial force in the cross section due to prestressing; and $A_{c}$ is the area of concrete cross section.

The part of shear strength provided by the fiber is determined as follows:

$$
V_{f b}=\frac{A_{f v} \sigma_{R d, f}}{\tan \theta}
$$

where $A_{f v}$ is the area of fiber effect and is assumed to be $b_{w} z$ for rectangular section; $z$ is the inner lever arm and is 
approximately equal to $0.9 d$; and $\theta$ is the angle between the principal compression stress and the beam axis, which a minimum value of $30^{\circ}$ is recommended; and $\sigma_{R d, f}$ is residual tensile strength and can be computed as follows:

$$
\begin{aligned}
\sigma_{R d, f} & =\frac{1}{K \gamma_{c f}} \frac{1}{w_{\lim }} \int_{0}^{w_{\lim }} \sigma_{f}(w) d w, \text { where } w_{\lim } \\
& =\max \left(w_{u}, w_{\max }\right)
\end{aligned}
$$

where $K$ is the fiber orientation factor assuming to be a value of $1.25 ; \sigma_{f}(w)$ is a function of the tensile stress and crack width; and $w_{\max }$ is the maximum crack width.

The shear strength by the vertical shear reinforcement is as follows:

$$
V_{s}=\frac{A_{v}}{s} z f_{y t} \cot \theta
$$

Meanwhile, ACI 544 (1988) provides shear strength for fiber-reinforced concrete proposed by Sharma (1986) as follows:

$$
V_{c f}=\frac{2}{3} f_{c t}\left(\frac{d}{a}\right)^{0.25} b_{w} d
$$

where $f_{c t}$ is splitting tensile strength of FRC.

\subsection{Minimum Shear Reinforcement}

Current design provisions (ACI 318-14 2014; EC2 2004; CSA A23.3-04 2004; AASHTO-LRFD 2004; MC2010 2012) for reinforced concrete $(\mathrm{RC})$ beam provide the minimum and maximum shear reinforcement as shown in Table 1. According to Section 9.6.3 of ACI 318-14 (2015), a minimum area of shear reinforcement should be provided in beams where the factored shear force $\left(V_{u}\right)$ exceeds $0.5 \phi_{c} V_{c}$. In Section 9.2.2 of EC2 (2004), when design shear force $\left(V_{d}\right)$ is higher than design shear resistance $\left(V_{d c}\right)$ provided by concrete $\left(V_{d}>V_{d c}\right)$, sufficient shear reinforcement should be provided in order that shear resistance $\left(V_{R d}\right)$ is larger than design shear force $\left(V_{d} \leq V_{R d}\right)$.

For fiber-reinforced concrete beams, when compressive strength $\left(f_{c}^{\prime}\right)$ is not exceeding $40 \mathrm{MPa}$, an overall height (h) not $>600 \mathrm{~mm}$, and the factored shear force not larger than $\phi 0.17 \sqrt{ } f_{c}^{\prime} b_{w} d$, the minimum shear reinforcement would not be required. Parra-Montesinos (2006) suggested that shear strength of FRC with hooked or crimped steel fibers exhibits greater than $0.29 \sqrt{ } f_{c}^{\prime} b_{w} d$.

\subsection{Spacing Limits for Shear Reinforcement}

ACI 318-14 (2014) prescribes the spacing limitation of shear reinforcement in Section 9.7.6.2.2. Spacing of shear reinforcement installed perpendicular to the axis of the member should not exceed $d / 2$ in beams nor $600 \mathrm{~mm}$. Where shear strength contributed by shear reinforcement $\left(V_{s}\right)$ exceeds $0.33 \sqrt{ } f_{c}^{\prime} b_{w} d$, maximum spacing should be reduced by one-half. EC2 suggests the spacing limits as $0.75 d$ or $600 \mathrm{~mm}$. In Section 11.3.8.1 of CSA A23.3-04 (2004), the spacing of shear reinforcement shall not exceed $0.7 d_{v}\left(d_{v}=\max (0.9 d, 0.72 h)\right)$ or $600 \mathrm{~mm}$ in case of beams with an overall thickness greater than $750 \mathrm{~mm}$. According to MC2010 (Section 7.13.5.2), shear reinforcement generally is provided in their spacing not exceed $0.75 d$ or $500 \mathrm{~mm}$. However, current design guidelines for UHPFRC members does not provide the spacing limits for shear reinforcement.

\section{Experimental Program}

\subsection{Specimen Description}

Test specimens which had a same dimension were designed in accordance with K-UHPC (2012) guidelines as shown in Fig. 1. As shown in Table 2, primary test parameter is the spacing $(s)$ of shear reinforcement. Figure 1a shows the cross-section of the test specimens. Rectangular cross-sectional specimens had a dimension $\left(b_{w} \times h\right)$ of $150 \times 290 \mathrm{~mm}$, where, $b_{w}$ is the beam width and $h$ is the overall height of the beam. The effective depth $(d)$ of the beam is $220 \mathrm{~mm}$ and the shear span to depth ratio $(a / d)$ is 3.0. Concrete cover is $30 \mathrm{~mm}$. To induce shear failure, four D29 $\left(d_{b}=29 \mathrm{~mm}\right) \quad$ high-strength reinforcements $\left(f_{y}=600 \mathrm{MPa}\right)$ were used, where $d_{b}$ is a diameter of reinforcing bars and $f_{y}$ is a design yield strength of reinforcement. The longitudinal reinforcement ratio $(\rho)$ is equal to the value of 0.078 . Shear reinforcement [D10 $\left(d_{b}=10 \mathrm{~mm}\right)$, $\left.f_{y t}=400 \mathrm{MPa}\right]$ was designed in accordance with ACI 318-14 (2014). Therefore, the moment capacities $\left(M_{n}\right)$ of all specimens were $338.3 \mathrm{kN} \mathrm{m}$ and shear strength corresponding to moment capacity was $512.6 \mathrm{kN}$.

The SB1 specimen is a control test specimen without shear reinforcement. (see Fig. 1b) This specimen was designed as

Table 1 Minimum shear reinforcement for RC beam in current design codes.

\begin{tabular}{c|c}
\hline Design codes & Minimum shear reinforcement \\
\hline \hline ACI 318-14 (2014) & $\rho_{v, \text { min }}=0.062 \sqrt{f_{c}^{\prime}} / f_{y t} \geq 0.35 / f_{y t}$ \\
\hline EC2 (2004) & $\rho_{v, \text { min }}=0.08 \sqrt{f_{c}^{\prime}} / f_{y t}$ \\
\hline CSA A23.3-04 (2004) & $\rho_{v, \text { min }}=0.06 \sqrt{f_{c}^{\prime}} / f_{y t}$ \\
\hline AASHTO-LRFD (2004) & $\rho_{v, \text { min }}=0.083 \sqrt{f_{c}^{\prime}} / f_{y t}$ \\
\hline MC2010 (2012) & $\rho_{v, \min }=0.08 \sqrt{f_{c}^{\prime}} / f_{y t}$ \\
\hline
\end{tabular}

$f_{c}^{\prime}$ is the compressive strength of concrete (in MPa) and $f_{y t}$ is the design yield strength of shear reinforcement (in MPa). 


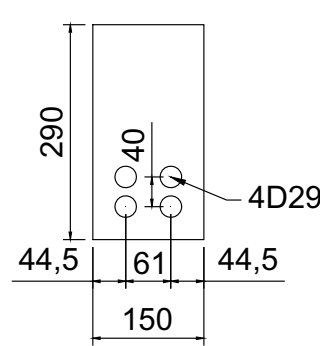

B1 specimen
(SD600)

\section{4,5}

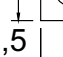

Q+

4D29 (SD600)
150

B2, B3, and B4 specimens

(a)

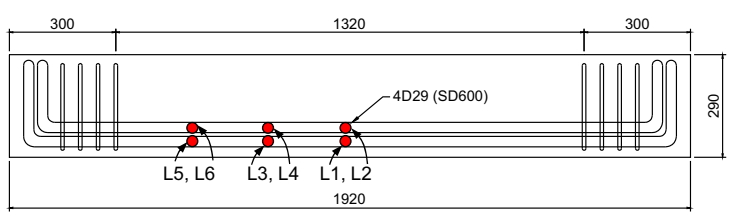

(b)

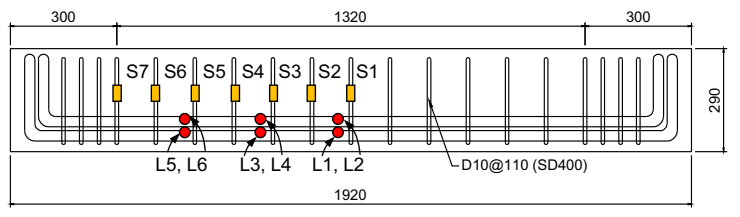

(d)

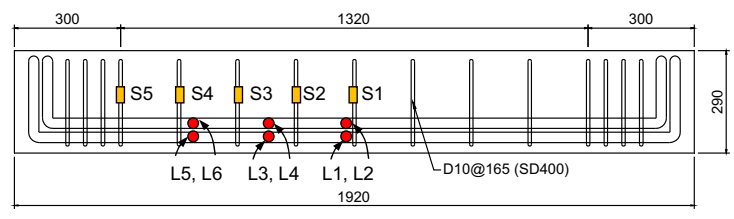

(c)

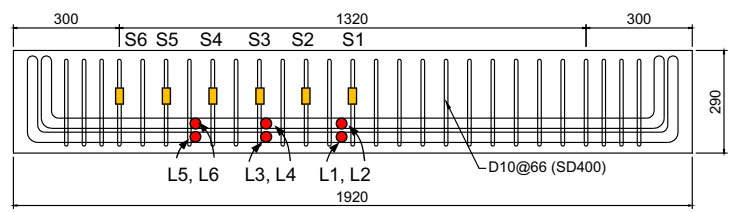

(e)

Fig. 1 Details of the test specimens (unit: $\mathrm{mm}$ ). a Cross section, b SB1 specimen, $\mathbf{c}$ SB2 specimen $(s=0.75 d)$, d SB3 specimen $(s=0.5 d)$, e SB4 specimen $(s=0.3 d)$.

Table 2 Test variables.

\begin{tabular}{|c|c|c|c|c|c|c|c|c|c|c|c|c|}
\hline Specimens & $f_{c t}(\mathrm{MPa})$ & $V_{f}(\%)$ & $a / d$ & $\rho_{l}(\%)$ & $\rho_{v}(\%)$ & $f_{y}(\mathrm{MPa})$ & $f_{y v}(\mathrm{MPa})$ & $s(\mathrm{~mm})$ & $\begin{array}{c}M_{n}(\mathrm{kN}- \\
\mathrm{m})\end{array}$ & $\begin{array}{l}V_{@ M n} \\
(\mathrm{kN})\end{array}$ & $V_{n}(\mathrm{kN})$ & $V_{@ M n} / V_{n}$ \\
\hline SB1 & 11.5 & 1.5 & 3 & 0.78 & - & 617.7 & 537.5 & - & 338.3 & 512.6 & 347.6 & 1.47 \\
\hline SB2 & 11.5 & 1.5 & 3 & 0.78 & 0.6 & 617.7 & 537.5 & 165 & 338.3 & 512.6 & 449.8 & 1.14 \\
\hline SB3 & 11.5 & 1.5 & 3 & 0.78 & 0.9 & 617.7 & 537.5 & 110 & 338.3 & 512.6 & 501.0 & 1.02 \\
\hline SB4 & 11.5 & 1.5 & 3 & 0.78 & 1.4 & 617.7 & 537.5 & 66 & 338.3 & 512.6 & 603.2 & 0.85 \\
\hline
\end{tabular}

$f_{c t}$ is measured tensile strength obtained using direct tension test; $V_{f}$ is fiber volume fraction; $a / d$ is the shear span-to-depth ratio; $\rho_{l}$ is the longitudinal reinforcement ratio $\left(A_{s} / b_{w} d\right)$; $\rho_{v}$ is the shear reinforcement ratio $\left(A_{s v} / b_{w} s\right) ; A_{s}$ is the area of the longitudinal reinforcement; $A_{s v}$ is the area of the shear reinforcement; $f_{y}$ is measured yield strength of longitudinal reinforcement; $f_{y v}$ is measured yield strength of shear reinforcement; $s$ is the spacing of shear reinforcement; $M_{n}$ is the flexural moment strength; $V_{@ M n}$ is the shear force at flexural moment strength; $V_{n}$ is the shear strength determined in accordance with JSCE and K-UHPC recommendations.

the specimen failed by diagonal tension failure $\left(V_{@ M n}>V_{n}\right)$. The SB2, SB3, and SB4 specimen has shear reinforcement with a spacing of $0.75 d \quad(165 \mathrm{~mm})$, $0.5 d(110 \mathrm{~mm})$ and $0.3 d(66 \mathrm{~mm})$, respectively (Figs. 1c to $1 \mathrm{e})$. Here, the spacing of $0.5 d$ is a spacing limit provided in ACI 318-14 (2014). In SB3 and SB4 specimens, shear reinforcements were provided at a spacing. Thus, the shear reinforcement ratios of SB2, SB3, and SB4 specimens were $0.6,0.9$ and $1.4 \%$, respectively.

\subsection{Test Set-Up and Instrumentation}

Figure 2 shows the test set-up and instrumentation. Simply supported beams were loaded with a capacity of $1000 \mathrm{kN}$ actuator by displacement control. Deflection of the beam

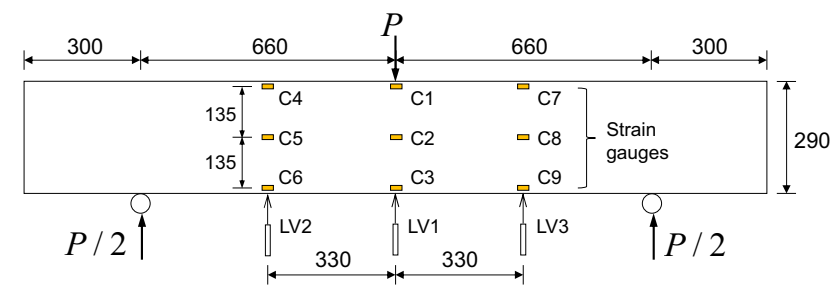

Fig. 2 Test set up (unit: $\mathrm{mm}$ ).

was measured using three Linear Vertical Displacement Transducers (LVDTs). One is installed at the mid-span of the beam and others are at one-half distance $(330 \mathrm{~mm})$ of both sides with respect to mid-span. 
Strains of the longitudinal and shear reinforcing bars was measured by using strain gauges during the tests. The location of the strain gauges is presented in Fig. 1. Strain distribution of concrete was obtained at top, mid-height, and bottom of the beam using strain gauges.

\section{Material Properties}

\subsection{Materials and Mix Design of UHPFRC}

The UHPFRC is a kind of reactive powder concrete that coarse aggregates were not included. Fine aggregates consist of sand with a diameter of $<0.5 \mathrm{~mm}$, which is the largest component of the UHPFRC. Portland cement is used as the binder, and the filler material is crushed quartz with an average diameter of $10 \mathrm{~lm}$ and a density of $2600 \mathrm{~kg} / \mathrm{m}^{3}$. The workability provided by the low water-to-cement ratio of the concrete is maintained by the addition of a high-performance water reducing agent, a polycarboxylate superplasticizer with a density of $1060 \mathrm{~kg} / \mathrm{m}^{3}$. In Table 3 , the proportions of the components are shown in terms of weight ratios.

Two different straight-shaped steel fibers with a diameter of $0.2 \mathrm{~mm}$ are used to produce the UHPFRC containing steel fibers. According to Park et al. (2012), the overall shape of tensile stress-strain curves of the UHPFRC was substantially dependent on the type of macro fibers. The addition of micro fibers had an effect on the strain hardening and multiple cracking behaviors. For each batch, UHPFRC includes both steel fibers with different lengths of 16 and $19 \mathrm{~mm}$. The fibers had a yield strength of $2500 \mathrm{MPa}$. Test specimens were produced after adding in a volume of $1.5 \%$ of the total mix volume.

\subsection{Compressive Behavior of UHPFRC}

Compression tests for cylindrical test specimens with a diameter of $100 \mathrm{~mm}$ and a height of $200 \mathrm{~mm}$ were performed to obtain the compressive strength of UHPFRC in accordance with ASTM C39/C39M (2005). Figure 3a shows stress-strain curves of the test specimens with a fiber volume fraction of $1.5 \%$. Compressive strength was measured using universal testing machine controlling by displacement and axial strain $\left(\varepsilon_{c}\right)$ was obtained using two strain gauges on the opposite surface of the test specimen. Loading rate was $0.3 \mathrm{~mm} / \mathrm{min}$ during the tests. The cylindrical test specimens were produced with each batch simultaneously and were cured by steam curing at a temperature above $90{ }^{\circ} \mathrm{C}$ for $48 \mathrm{~h}$, and then they cured at room temperature for 60 days until testing.

The UHPFRC showed a linear-elastic behavior until the end of the test. After reaching the peak strength, a brittle failure occurred as shown in Fig. 3b. However, a post-peak behavior was not observed in all of the test specimens. The average compressive strength $\left(\sigma_{c u}\right)$ and ultimate strain $\left(\varepsilon_{c u}\right)$ were determined to be $166.9 \mathrm{MPa}$ and $0.0041 \mathrm{~mm} / \mathrm{mm}$, respectively. The modulus of elasticity $\left(E_{c}\right)$ was a value of 41.1 GPa, where it was calculated using ultimate stress and strain corresponding to ultimate stress under stress-strain relationship in accordance to AFGC design recommendations (2013).

\subsection{Tensile Behavior of UHPFRC}

The tensile strength of UHPFRC was obtained using direct tension tests for dog-bone shaped specimens in accordance with K-UHPC (2012) guidelines as shown in Fig. 4a. Test specimens had an overall width of $125 \mathrm{~mm}$, a height of $300 \mathrm{~mm}$, and a thickness of $25 \mathrm{~mm}$, but an effective width and a height are 75 and $150 \mathrm{~mm}$, respectively. To induce critical crack at the center of the specimen, notches were installed at both sides of the specimen. The length $\left(a_{0}\right)$ and width of the notches was 12.5 and $2 \mathrm{~mm}$, respectively.

Test specimens are loaded with $100 \mathrm{kN}$ actuator by displacement control. During the test, a loading speed is $0.3 \mathrm{~mm} / \mathrm{min}$. The tensile stress was computed with the load divided by an effective cross-sectional area of the specimen, which is equal to $(75-2 \times 12.5) \times 25 \mathrm{~mm}=1250 \mathrm{~mm}^{2}$. The effective cross-sectional area is defined as the area considering the width except for the overall notch length.

Figure $4 \mathrm{~b}$ shows tensile strength-crack opening relationship of the notched specimens. Crack opening was measured using clip gauges with a capacity of $10 \mathrm{~mm}$ installing at both notches. As shown in Fig. 4b, after reaching the peak tensile stress, the stress gradually decreased as increasing the crack opening. The significant variation of the peak tensile stress is because the non-uniform distribution of the steel fibers at the notch tip. Test results showed that the average tensile stress $\left(f_{c t}\right)$ was $11.5 \mathrm{MPa}$.

\subsection{Tensile Behavior of Reinforcing Bars}

Uniaxial tension tests for D29 $\left(d_{b}=29 \mathrm{~mm}\right.$, $\left.f_{y}=600 \mathrm{MPa}\right)$ and $\mathrm{D} 10\left(d_{b}=10 \mathrm{~mm}, f_{y t}=400 \mathrm{MPa}\right)$ reinforcing bars were also carried out in accordance with ASTM A370-14 (2014). The average tensile stresses of longitudinal (D29) and shear (D10) reinforcement were 617.7 and $537.5 \mathrm{MPa}$, respectively.

\section{Test Results}

\subsection{Damage and Crack Patterns}

The amount of shear reinforcement greatly affected the damage and crack patterns for UHPFRC rectangular crosssectional beams $\left(V_{f}=1.5 \%\right)$. Figure 5 shows damage and

Table 3 Mix proportion (weight ratio).

\begin{tabular}{c|c|c|c|c|c}
\hline Water-binder ratio & Cement & Zirconium & Filler & Fine aggregate & $\begin{array}{c}\text { Water-reducing } \\
\text { admixture }\end{array}$ \\
\hline \hline 0.2 & 1.0 & 0.25 & 0.3 & 1.1 & 0.02 \\
\hline
\end{tabular}




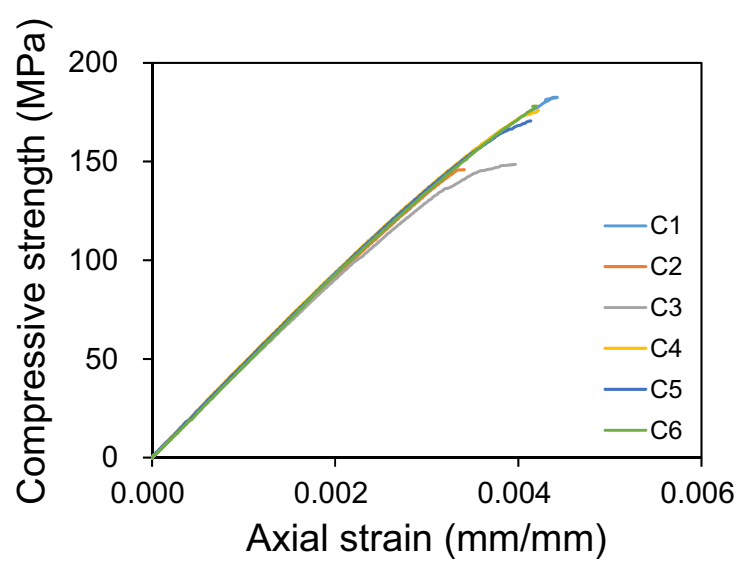

(a)

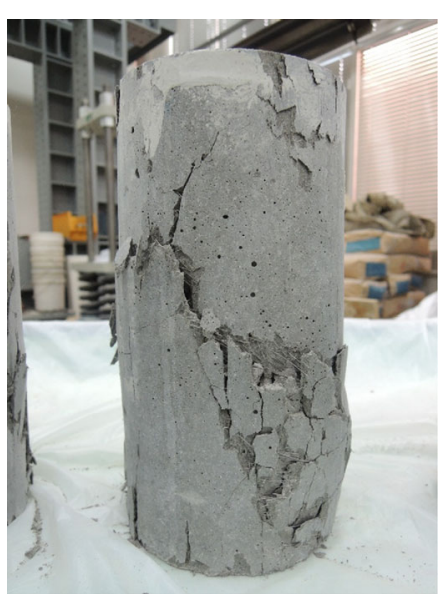

(b)

Fig. 3 Uniaxial compression test for UHPFRC. a Stress-strain curves, b failure mode.

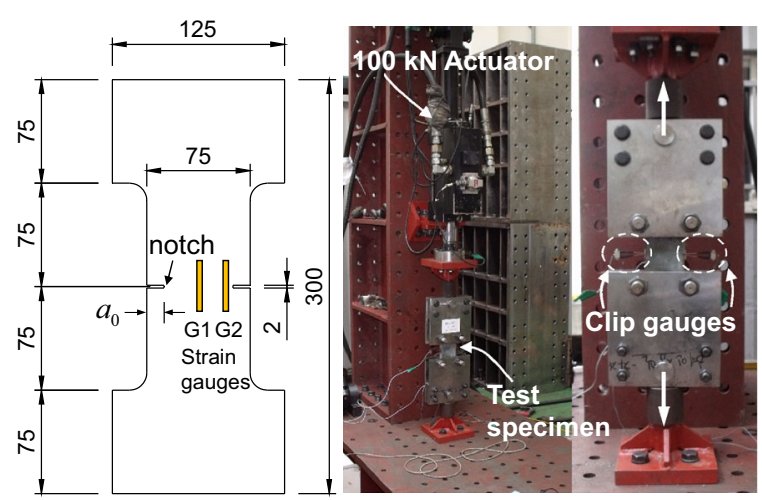

(a)

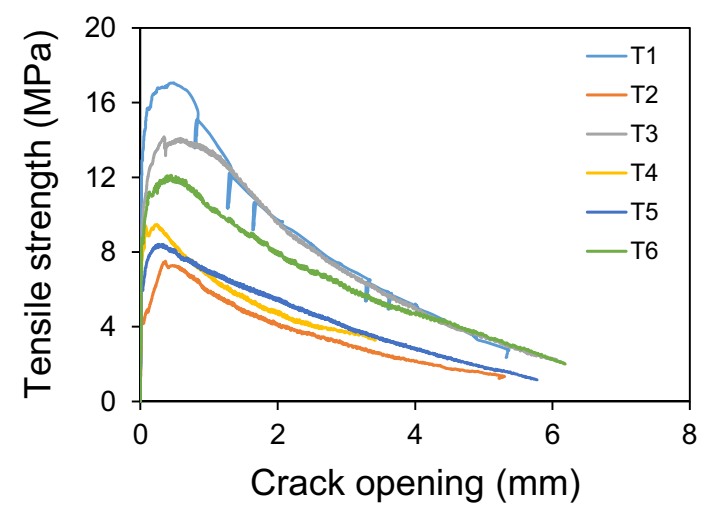

(b)

Fig. 4 Direct tensile test for UHPFRC. a Dog-bone shaped specimen, b stress-strain curves.

crack patters at the end of the tests. For control specimen SB1 which does not contain the shear reinforcement, flexural cracks initiated at the bottom of beam at the mid-span, and then the diagonal cracks occurred at the end of the flexural cracks. Finally the diagonal tension failure occurred after the yielding of longitudinal reinforcing bars. In this specimen,
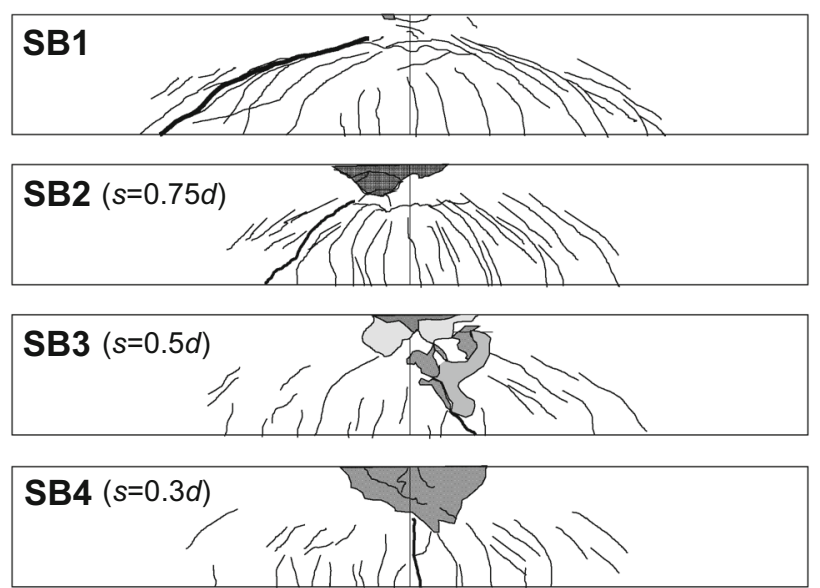

Fig. 5 Damage and crack patterns at the end of the test. compression failure at the compression zone was also observed with shear cracks.

In case of SB2 specimen, a diagonal tension failure as well as the compression failure of concrete occurred and shear reinforcement yielded prior to the yielding of longitudinal reinforcement. In this specimen, the compression failure and the yielding of longitudinal reinforcement occurred almost simultaneously. The specimen SB3 adopted the minimum shear reinforcement $(s=0.5 d)$ in accordance with ACI 318-14 (2014) showed a compression failure of concrete at the compression zone occurred prior to shear failure. The inclined shear cracks were developed subsequently after the flexural yielding of longitudinal reinforcing bars. For SB4 specimen installing the shear reinforcement at the spacing of $0.3 d$, flexural failure occurred without observation of critical shear cracks due to the excessive amount of shear reinforcement. After the compression failure of concrete, the yielding of longitudinal and shear reinforcement was followed. Test results indicated that if the minimum shear reinforcement is installed at a spacing of $0.5 \mathrm{~d}$ presented in ACI 318-14 (2014), the flexural failure may occur prior to shear failure. On the other hand, for beams with the spacing 
which is greater than minimum values in current design codes, the yielding of shear reinforcement might be observed prior to the yielding of flexural reinforcement and compression failure.

\subsection{Load-Displacement Relationship}

Figure 6a shows the load-displacement relationship of test specimens. Here, the displacement is a deflection measured at the mid-span of the beam. Figure $6 \mathrm{~b}$ depicts definition of yielding point and ductility. The value of $V_{y}$ is the yield strength, $V_{\text {peak }}$ is the peak shear strength, $V_{\text {failure }}$ is the strength at failure, $\Delta_{y}, \Delta_{@ V \text { peak }}$ and $\Delta_{\text {failure }}$ are the displacement corresponding to the strength of $V_{y}, V_{\text {peak }}$ and $V_{\text {failure }}$, respectively. The displacement at failure is defined as the deflection when the load dropped to $80 \%$ of the peak load. The secant stiffness at a point of two-third of the measured peak strength is used to idealize the elastoplastic curve that passes through the peak point of the load-displacement curve, and the displacement at an intersecting point between the two lines is used to determine the yield point on the curve (Pan and Moehle 1989). The ultimate shear strengths of the UHPFRC beams are reported in Table 4 in terms of the average shear stress which is defined as the peak shear force divided by the beam width and effective depth $\left(v_{u}=V_{u} / b_{w} d\right)$. The ductility $(\mu)$ is defined as the ability of the structure or parts of it to sustain large deformations beyond the yield point, which is obtained in terms of displacements, as the maximum displacement $\left(V_{\text {failure }}\right)$ divided with the yield displacement $\left(\Delta_{y}\right)$.

As shown in Fig. 6, the peak load of the beams with shear reinforcement was greater than the beams without shear reinforcement. However, initial stiffness was very similar regardless of the presence of shear reinforcement and their spacing. For the control specimen (SB1), non-linear behavior showed after reaching the yielding point due to the yielding of longitudinal reinforcing bars and flexural cracks. Eventually the load suddenly dropped due to the diagonal tension failure after reaching the peak load. In case of the specimen SB2, SB3, and SB4, the strength was maintained almost being constantly at the peak strength, and then the strength dropped abruptly due to the compression failure at the compression zone without critical shear cracks even though several inclined cracks occurred. Unlike the control specimen, the strength gradually decreased due to the shear reinforcement after the compression failure of concrete. However, the peak strength of the beams with shear reinforcement was very similar. These results indicated that the shear reinforcement ratio might not influence on the peak strength of UHPFRC beams with shear reinforcement.

Shear reinforcement also had an effect on improvement of deformation capacity. Ductility $(\mu)$ of beams with shear reinforcement also appeared to be somewhat higher than the control specimen. The ductility of the control specimen was 2.04 and in case of the specimens with shear reinforcement (SB2, SB3, and SB4) were between 2.15 and 2.23.

\subsection{Strain Response}

Figure 7 shows the strain response of the test specimens. To measure the strains, strain gauges were used. Flexural yielding and shear yielding are defined as the point when the strain of the reinforcing bars reaches a yield strain $(=0.002)$. Also, a concrete failure is defined as a failure at the compression zone of the beam, that is, the compressive strain at the extreme fiber of the beam reaches an ultimate limit state of the UHPFRC. To define the ultimate state of the UHPFRC, the ultimate strain determined using material tests was used. Material tests showed that the ultimate strain of UHPFRC was between 0.003 and 0.0032 . The specimen SB1 shows the diagonal tension failure after flexural yielding. In this specimen, the flexural yielding occurred prior to concrete failure. For SB2 specimen installed shear reinforcement at the spacing of $0.75 d$, shear reinforcement yielded before flexural yielding and concrete failure. In case of the SB3 specimen, a flexural-shear failure occurred. The strain of shear reinforcement reaches the yield strain after flexural yielding and concrete failure. On the other hand, the SB4 specimen which is over-reinforced beam shows that shear yielding occurred before the flexural yielding, but after concrete compressive failure. As shown in Fig. 5, the ultimate failure mode was the compressive concrete failure. In this study, a critical shear crack was not observed during the tests.
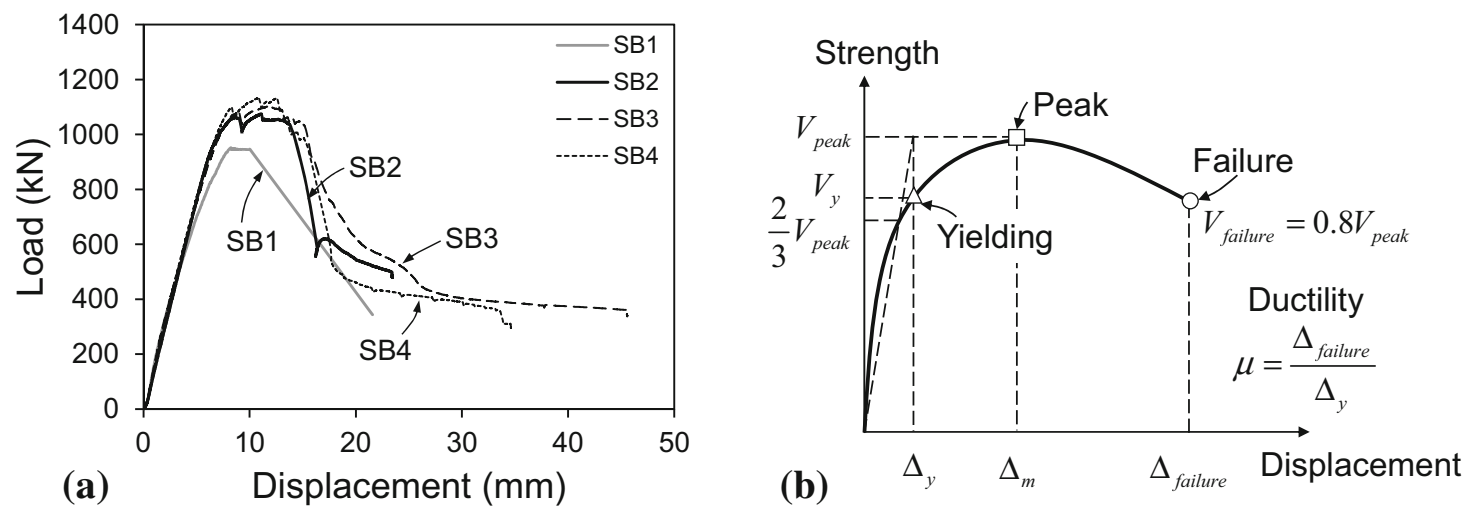

Fig. 6 Load-displacement relationship and definition of yielding point. a Load-displacement relationship, b definition of yielding point and ductility. 
Table 4 Summary of test results.

\begin{tabular}{c|c|c|c|c|c|c|c|c|c|c|c|c}
\hline Specimens & \multirow{2}{*}{$\begin{array}{c}\text { Failure } \\
\text { mode }\end{array}$} & \multicolumn{2}{|c|}{ At initial cracking } & \multicolumn{2}{|c|}{ At yielding } & \multicolumn{2}{|c|}{ At peak } & \multicolumn{2}{|c|}{ At failure } & $\begin{array}{c}V_{\text {test }} \\
(\mathrm{MPa})\end{array}$ & $\begin{array}{c}v_{\text {test }} \\
\sqrt{f_{c f}} \\
(\mathrm{MPa})\end{array}$ & $\begin{array}{c}\mu \\
\left(\Delta_{\text {failure }}\right. \\
\left.\Delta_{y}\right)\end{array}$ \\
\hline \hline $\mathrm{SB} 1$ & $\mathrm{~S}$ & 2.1 & 339.7 & 6.7 & 347.8 & 8.2 & 475.8 & 26.4 & 172.0 & 14.4 & 1.12 & 2.04 \\
\hline $\mathrm{SB} 2$ & $\mathrm{SY}$ & 1.1 & 150.2 & 7.1 & 479.1 & 11.1 & 537.3 & 15.3 & 408.9 & 16.3 & 1.26 & 2.15 \\
\hline $\mathrm{SB} 3$ & $\mathrm{C}$ & 3.6 & 555.6 & 7.3 & 359.8 & 11.8 & 551.7 & 16.3 & 441.0 & 16.7 & 1.29 & 2.23 \\
\hline $\mathrm{SB} 4$ & $\mathrm{~F}$ & 1.2 & 190.5 & 7.3 & 296.1 & 10.9 & 567.0 & 16.0 & 436.1 & 17.2 & 1.33 & 2.19 \\
\hline
\end{tabular}

$V_{c r}$ is the initial cracking strength; $V_{y}, V_{\text {peak }}$, and $V_{\text {failure }}$ are the yield strength, peak strength, shear strength at failure, respectively. $\Delta_{c r}, \Delta_{y}$, $\Delta_{@ V \text { peak }}$, and $\Delta_{\text {failure }}$ are the measured displacement corresponding to the strength of $V_{c r}, V_{y}, V_{\text {peak }}$, and $V_{\text {failure }}$ at the mid-span of the test specimen, respectively. $\mu$ is the ductility obtained by the equations of $\Delta_{\text {failure }} / \Delta_{y}$. It should be note that $\mathrm{S}$ means the diagonal tension failure; $\mathrm{SY}$ is the shear yielding; $\mathrm{C}$ is the compression failure of concrete; $\mathrm{F}$ is the flexural yielding.

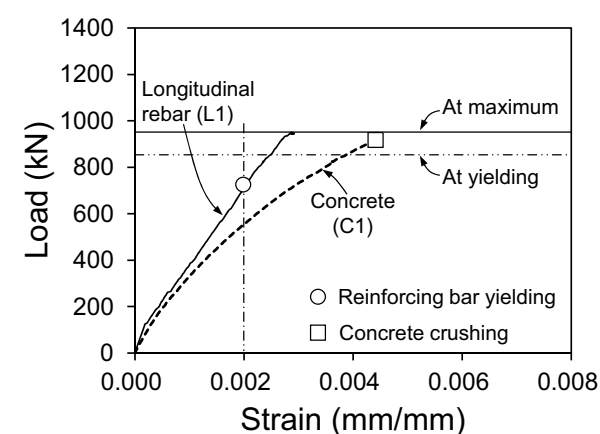

(a)

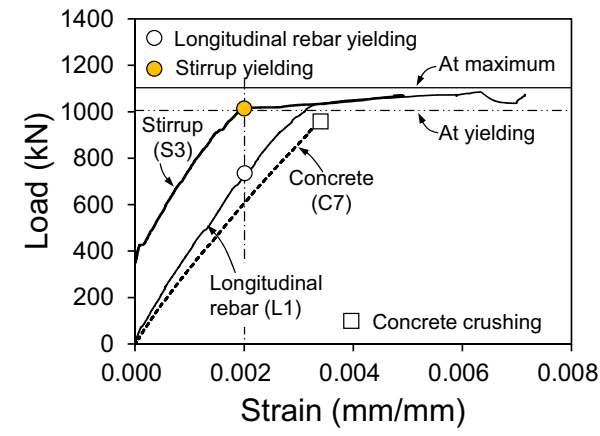

(c)

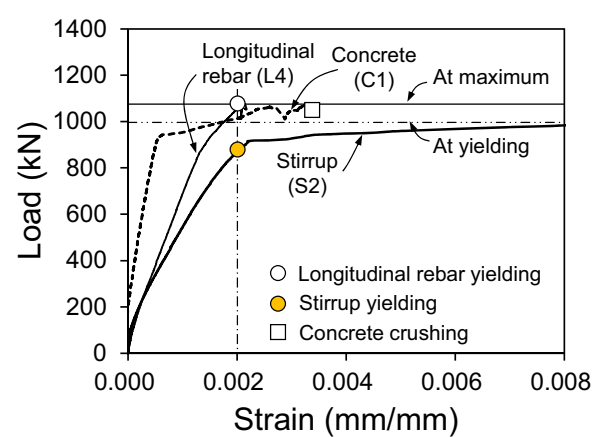

(b)

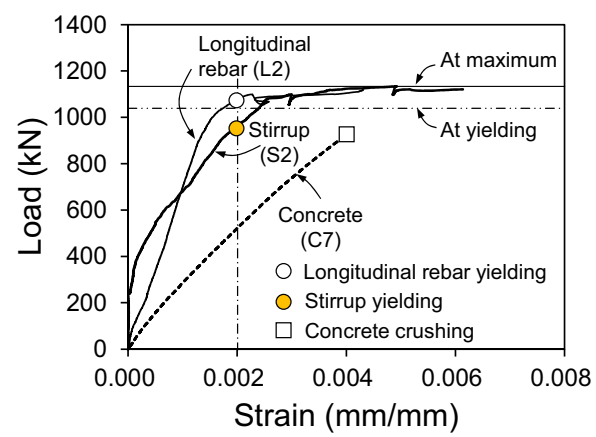

(d)

Fig. 7 Measured strain values of concrete, longitudinal and shear reinforcement. a SB1, b SB2 $(s=0.75 d)$, c SB3 $(s=0.5 d)$, d SB4 $(s=0.3 d)$.

\section{Discussion of Test Results}

\subsection{Effect of Shear Reinforcement on Shear Strength}

The ultimate shear strength of the UHPFRC beams was dependent on the presence of shear reinforcement. The shear strength of the beams with shear reinforcement was larger than that of control specimen and was improved about 13-19\%. However, the effect of the amount of shear reinforcement was insignificant. Although the area of shear reinforcement increases about $55.6 \%$ with respect to the current design codes, the increase of shear strength was only about $2.6 \%$ (in case of SB3 and SB4). In addition, provided that the amount of shear reinforcement decreases about $37.5 \%$ regarding the minimum shear reinforcement, deterioration of the shear strength was in about $2.6 \%$. These results indicated that the steel fibers substantially contribute to enhancement of the shear resistance of UHPFRC beams. The shear contributions of UHPFRC are reported in Table 5, where the shear resistances $\left(V_{c}, V_{f b}\right.$, and $\left.V_{s}\right)$ are obtained using AFGC recommendations. As shown in Table 5, current design guidelines had some conservatism to the test results. Among the component of shear resistance for the beams, shear strength provided by steel fibers was determined to be the greatest value regardless of shear reinforcement. Especially, in case of the control specimen, the shear strength was more largely affected by the shear contribution of steel fibers $\left(V_{\text {test }} / V_{f b}=1.76\right)$ than cement matrix $\left(V_{\text {test }} / V_{c}=6.2\right)$. On the other hand, in case of the specimens with shear reinforcement, the shear resistances were affected by shear contributions by steel fibers and shear reinforcement. As increasing the amount of shear reinforcement, 
Table 5 Shear contributions of UHPFRC.

\begin{tabular}{c|c|c|c|c|c|c|c|c|c|c|c}
\hline Specimens & $s(\mathrm{~mm})$ & $V_{c}(\mathrm{kN})$ & $V_{f b}(\mathrm{kN})$ & $V_{s}(\mathrm{kN})$ & $V_{\text {test }}(\mathrm{kN})$ & $\frac{V_{\text {test }}}{V_{c}}$ & $\frac{V_{\text {test }}}{V_{f b}}$ & $\frac{V_{\text {test }}}{V_{s}}$ & $\frac{V_{\text {test }}}{V_{c}+V_{f b}}$ & $\frac{V_{\text {test }}}{V_{f b}+V_{s}}$ & $\frac{V_{c}+V_{f b}+V_{s}}{V_{c}}$ \\
\hline \hline $\mathrm{SB} 1$ & - & 76.7 & 270.9 & - & 475.8 & 6.20 & 1.76 & - & 1.37 & 1.76 & 1.37 \\
\hline $\mathrm{SB} 2$ & $0.75 d$ & 76.7 & 270.9 & 102.2 & 537.3 & 7.01 & 1.98 & 5.26 & 1.55 & 1.44 & 1.19 \\
\hline $\mathrm{SB} 3$ & $0.5 d$ & 76.7 & 270.9 & 153.4 & 551.7 & 7.19 & 2.04 & 3.60 & 1.59 & 1.30 & 1.10 \\
\hline $\mathrm{SB} 4$ & $0.3 d$ & 76.7 & 270.9 & 255.6 & 567.0 & 7.39 & 2.09 & 2.22 & 1.63 & 1.08 & 0.94 \\
\hline
\end{tabular}

$s$ is the spacing of shear reinforcement; $d$ is the effective depth; $V_{c}, V_{f b}$, and $V_{s}$ are shear strength provided by cement matrices, steel fiber and shear reinforcement obtained in accordance with AFGC design guidelines (2013); and $V_{\text {test }}$ is the peak shear force determined from the tests.

shear contribution provided by shear reinforcement decreased. However, if the spacing of shear reinforcement is $0.75 d\left(\rho_{v}=0.9 \%\right)$, the effect of shear resistance provided by shear reinforcement decreased while the shear contribution by steel fibers increased. If the shear reinforcement provides in about $1.4 \%(s=0.3 d)$, the shear contributions by steel fibers and shear reinforcement was very similar ( $V_{\text {test }} / V_{f b}=2.09$ and $V_{\text {test }} / V_{s}=2.22$ ) even though the shear resistance is larger than test results. On the contrary to this, in case of the UHPFRC beam with a shear reinforcement ratio of $0.6 \%$, the effect of the shear reinforcement was less significant than other reinforced beams.

From these results, it is found that the steel fibers irregularly distributed on the diagonal cracked section play a key role to restrain the shear crack along with the shear reinforcement.

\subsection{Evaluation of Shear Strength}

The shear strength predictions of FRC beams were evaluated as to whether or not they are applicable to UHPFRC beams. For comparisons, the existing shear strength models for SFRC beams proposed by Sharma (1986), Narayanan et al. (1987), Ashour (1992), ACI 544 (1997), Kwak et al. (2002) were used. They are summarized in Table 6.
Sharma (1986) investigated the effect of steel fibers on shear strength performing seven SFRC beams with a compressive strength of about $45 \mathrm{MPa}$. From their shear tests, it is found that steel fibers are effective in increasing the shear strength and SFRC beams have a high post-cracking strength. Narayanan and Darwish (1987) carried out shear tests for forty-nine SFRC rectangular cross-sectional beams with a compressive strength of 40-79.5 MPa regarding shear span to depth ratio $(a / d)$, longitudinal and shear reinforcement, presence of shear reinforcement, and the fiber factor $\left(F=(L / D) \rho_{f} d_{f}\right)$. Based on the observations of first cracks in shear, empirical shear strength equation was suggested for the evaluation of cracking shear strength. Ashour et al. (1992) tested eighteen HSFRC beams $\left(f_{c}^{\prime}=93 \mathrm{MPa}\right)$ with or without shear reinforcement. Test variables were shear span-to-depth $(a / d)$, longitudinal reinforcement ratio, fiber volume fraction. They found that shear strength of beams increase with an increase of fiber volume fraction and a decrease in $a / d$. On the basis of test results, predictions of shear strength for high-strength SFRC beams without shear reinforcement. ACI 544 (1997) adopted the shear strength equations proposed by Sharma (1986) based on the test results. The proposed equations follows the method of $\mathrm{ACI}$ 318 for calculating the contribution of stirrups to the shear

Table 6 Existing shear strength models.

\begin{tabular}{c|c}
\hline Authors & Shear strength models \\
\hline \hline Sharma (1986) & $v_{u}=k f_{t}^{\prime}(d / a)^{0.25}$ \\
& $\begin{array}{c}\text { where } k=2 / 3 ; a / d \text { is the shear span-to-depth ratio; } f_{t}^{\prime}=0.17 \sqrt{ } f_{c f}, \text { if } \\
\text { the tensile strength is unknown, and } f_{c f} \text { is the concrete cylinder } \\
\text { compressive strength }\end{array}$ \\
\hline
\end{tabular}

where $f_{\text {spfc }}$ is the computed split-cylinder strength of fiber concrete

$\left(=f_{\text {cuf }} /(20-\sqrt{ } F)+0.7+1.0 \sqrt{ } F\right) ; \rho$ is the longitudinal reinforcement ratio; $\mathrm{F}$ is the fiber factor $\left(=\left(L_{f} / D_{f}\right) V_{f} d_{f} ; e\right.$ is the arch action factor, 1.0 for $a / d>2.8$ and $2.8 d / a$ for $a / d \leq 2.8 ; f_{\text {cuf }}$ is the cube strength of fiber concrete; $V_{f}$ is the fiber volume fraction; $d_{f}$ is a bond factor, 0.5 for round fibers, 0.75 for crimped fibers, and 1.0 for indented fibers; $v_{b}$ is equal to the equations of $0.41 \tau F$, and $\tau$ is the average fiber matrix interfacial bond stress, taken as $4.15 \mathrm{MPa}$

\begin{tabular}{c|c}
\hline Ashour et al. (1992) & For $a / d \geq 2.5 v_{u}=\left(2.11 \sqrt[3]{f_{c f}}+7 F\right)\left(\rho \frac{d}{a}\right)^{1 / 3}$ \\
\hline Kwak et al. (2002) & $v_{u}=3.7 e f_{s p f c}^{2 / 3}\left(\rho \frac{d}{a}\right)^{1 / 3}+0.8 v_{b}$
\end{tabular}

where $e$ is the arch action factor, 1 for $a / d>3.4$, and 3.4d/a for $a /$ $d \leq 3.4$ 
capacity, to which is added the resisting force of the concrete calculated from the shear stress. Kwak et al. (2002) performed twelve four-point shear tests for normal(30.8 MPa) and high-strength (68. 6 MPa) SFRC beams without shear reinforcement considering fiber volume fraction $\left(V_{f}=0,0.5,0.75 \%\right)$ and shear span to depth ratio $(a /$ $d=2,3$, and 4). Shear strength equations for shear cracking was proposed to improve the accuracy of existing procedures suggested by Narayanan and Darwish (1987).

As shown in Table 7, the existing shear strength equations for SFRC beams were very conservative compared to the experimental data. This means that they would be unreasonable to predict the shear strength of the UHPFRC beams with a compressive strength more than $160 \mathrm{MPa}$. On the other hand, AFGC recommendations (2013) showed a relatively accurate evaluations of UHPFRC beams with and without shear reinforcement.

\subsection{Steel Fibers as Shear Reinforcement}

According to ACI 318-14 (2014), when the normalized shear strength $\left(v_{\text {test }} / \sqrt{ } f_{c}^{\prime}\right)$ defined as divided the average shear stress by the square root of the compressive strength is greater than $0.29 \sqrt{ } f_{c}^{\prime}(\mathrm{MPa})$, the steel fibers can use as the shear reinforcement for SFRC beam $\left(f_{c}^{\prime} \leq 40 \mathrm{MPa}\right.$, $d \leq 600 \mathrm{~mm}$ ). Parra-Montesinos found that the shear strength of SFRC beam strength was larger than $0.3 \sqrt{ } f_{c}^{\prime}$ $(\mathrm{MPa})$ when fiber content $\left(V_{f}\right)$ is equal to or greater than $0.75 \%$.

Normalized shear strengths were evaluated whether or not current design codes are applicable to UHPFRC beams with shear reinforcement. As reported in Table 4, normalized shear strengths of all the specimens with $V_{f}=1.5 \%$ were larger than $1.12 \sqrt{ } f_{c}^{\prime}(\mathrm{MPa})$ regardless of the presence of shear reinforcement and its spacing as shown in Fig. 8.

These results indicate that if the rectangular beam contains UHPFRC with fiber volume fraction of $1.5 \%$, shear reinforcement need not be provided.

\subsection{Spacing Limit of Shear Reinforcement for UHPFRC Beam}

As aforementioned, current design codes for reinforced concrete beam provide the spacing limit of shear reinforcement as $0.5 d$ in ACI 318-14 (2014) when the factored shear force $\mathrm{Vu}$ exceeds $0.5 \phi V_{c}$. Also, CSA A23.3-04 (2004) suggests its distance as $0.7 d_{v}$, where $d_{v}$ is a maximum value between $0.9 d$ and

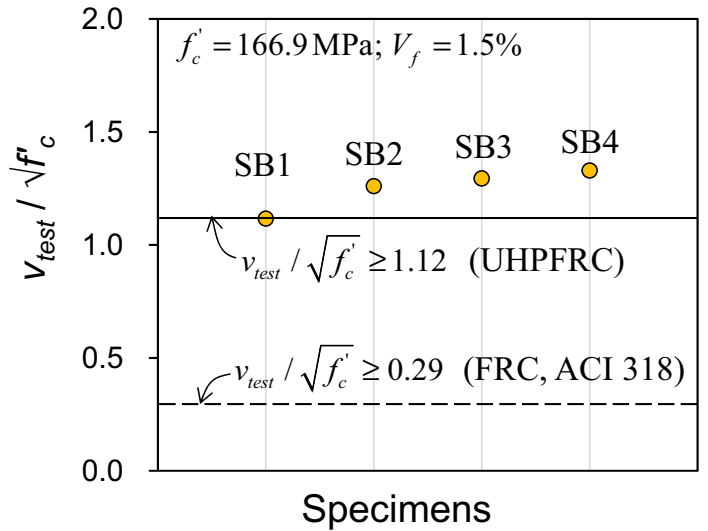

Fig. 8 Lower bound of normalized shear strength for UHPFRC.

$0.72 h$. To investigate the effect of spacing limit, this study considered the distance of $0.75 d, 0.5 d$, and $0.3 d$.

Test results showed that even though the spacing of shear reinforcement exceeds the spacing limit recommended by ACI 318-14 (2014), shear strength of UHPFRC beam was substantially greater than current design codes. Based on the test results, it is concluded that the spacing limit of $0.75 \mathrm{~d}$ can be allowed for UHPFRC beams.

\section{Summary and Conclusions}

In this study, shear tests on simply supported UHPFRC rectangular beam sections with and without shear reinforcement were carried out to investigate the shear behaviour considering the spacing of shear reinforcement. The main test parameter was the spacing of shear reinforcement. Findings obtained through the experiments are as follows:

1. Compression and direct tension tests were carried out to investigate the material properties of UHFRC. The UHPFRC used in this study showed a linear-elastic behavior until the end of the test and a brittle failure occurred after reaching the peak strength, not observing a post-peak behavior in all of the test specimens. The average compressive strength was $166.9 \mathrm{MPa}$ and the modulus of elasticity was about $41.1 \mathrm{GPa}$. Also, tensile strength of UHPFRC obtained using direct tension tests was determined to be about 11.5 MPa.

Table 7 Comparison between the predicted strength and test data.

\begin{tabular}{c|c|c|c|c|c}
\hline Specimens & Sharma (1986) & $\begin{array}{c}\text { Narayanan and } \\
\text { Darwish (1987) }\end{array}$ & Ashour et al. (1992) & Kwak et al. (2002) & AFGC (2013) \\
\hline \hline SB1 & 2.79 & 3.71 & 6.30 & 3.12 & 1.37 \\
\hline SB2 & 2.09 & 2.56 & 3.58 & 2.27 & 1.19 \\
\hline SB3 & 2.28 & 2.86 & 4.18 & 2.49 & 1.10 \\
\hline SB4 & 2.46 & 3.15 & 4.83 & 2.65 & 0.94 \\
\hline Mean & 2.41 & 3.07 & 4.72 & 0.36 & 0.08 \\
\hline SD & 0.30 & 0.49 & 1.17 & & \\
\hline
\end{tabular}


2. The steel fibers substantially contributes to enhancement of the shear resistance of UHPFRC beams. The shear strength of the beams with shear reinforcement was larger than that of control specimen and was improved about 13-19 \%. In addition, the steel fibers in UHPFRC beam play a key role to restrain the shear crack along with the shear reinforcement.

3. Shear reinforcement also had an effect on improvement of deformation capacity. The ductility of beams with shear reinforcement also appeared to be higher than the control specimen. The ductility of the control specimen was 2.04 and in case of the specimens with shear reinforcement (SB2, SB3, and SB4) were between 2.15 and 2.23 .

4. The AFGC recommendations (2013) showed a relatively accurate evaluations of UHPFRC beams with and without shear reinforcement compared to the existing shear strength equations for SFRC beams.

5. Even though the spacing of shear reinforcement exceeds the spacing limit suggested by current design code (ACI 318-14), shear strength of UHPFRC beam was substantially greater than current design codes. Therefore, the spacing limit of $0.75 d$ can be allowed for UHPFRC beams.

\section{Acknowledgments}

This research was supported by a grant (13SCIPA02) from Smart Civil Infrastructure Research Program funded by Ministry of Land, Infrastructure and Transport (MOLIT) of Korean government and Korea Agency for Infrastructure Technology Advancement (KAIA).

\section{Open Access}

This article is distributed under the terms of the Creative Commons Attribution 4.0 International License (http://creativecommons.org/licenses/by/4.0/), which permits unrestricted use, distribution, and reproduction in any medium, provided you give appropriate credit to the original author(s) and the source, provide a link to the Creative Commons license, and indicate if changes were made.

\section{References}

ACI Committee 318. (2014). Building Code Requirements for Structural Concrete (ACI 318M-14) and Commentary (318R-14). Farmington Hills, MI: American Concrete Institute.

ACI Committee 544. (1988). Design considerations for steel fiber reinforced concrete. ACI Structural Journal, 85(5), $1-18$.

Alaee, F. J., \& Karihaloo, B. L. (2003). Retrofitting of reinforced-concrete beams with CARDIFRC. Journal of Composites for Construction ASCE, 7(3), 174-186.
American Association of State Highway and Transportation Officials. (2004). AASHTO LRFD Bridge Design Specification (3rd ed.). Washington, DC: AASHTO.

Ashour, S. A., Hasanain, G. S., \& Wafa, F. F. (1992). Shear behavior of high-strength fiber reinforced concrete beams. ACI Structural Journal, 89(2), 176-184.

Association Française du Génil Civil (AFGC). (2013). Bétons fibrés àultra-hautes performances, Association Française du Génil Civil.

ASTM A370-14. (2014). Standard test methods and definitions for mechanical testing of steel products. West Conshohocken, PA: ASTM International.

ASTM C39/C39M-05. (2005). Standard test method for compressive strength of cylindrical concrete specimens. West Conshohocken, PA: ASTM International.

Baby, F., Marchand, P., \& Toutlemonde, F. (2014). Shear behavior of ultrahigh performance fiber-reinforced concrete beams. I: Experimental investigation. Journal of Structural Engineering ASCE, 140(5), 04013111.

CSA A23.3-04. (2004). Design of concrete structures. Rexdale, ON: Canadian Standard Association.

EN 1992-1-1. (2004). Eurocode 2: Design of Concrete Structures-Part 1-1: General Rules and Rules for Buildings. British Standards Institution.

Ezeldin, S., \& Balaguru, P. N. (1997). Normal- and highstrength fiber-reinforced concrete under compression. $A C I$ Material Journal, 94(4), 286-290.

Fanella, D. A., \& Naaman, A. E. (1985). Stress-strain properties of fiber reinforced mortar in compression. ACI Journal, 82(4), 475-483.

Farhat, F. A., Nicolaides, D., Kanellopoulos, A., \& Karihaloo, B. L. (2007). High performance fiber-reinforced cementitious composite (CARDIFRC) - performance and application to retrofitting. Engineering Fracture Mechanics, 74, 151-167.

Japan Society of Civil Engineers (JSCE). (2004). Recommendations for Design and Construction of Ultra-High Strength Fiber Reinforced Concrete Structures, draft.

Khuntia, M., Stojadinovic, B., \& Goel, S. C. (1999). Shear strength of normal and high-strength fiber reinforced concrete beams without stirrups. ACI Structural Journal, 96(2), 282-289.

Korea Concrete Institute. (2012). Design recommendations for ultra-high performance concrete (K-UHPC), KCI-M-12003, Korea (in Korean).

Kwak, Y. K., Eberhard, M. O., Kim, W. S., \& Kim, J. B. (2002). Shear strength of steel fiber-reinforced concrete beams without stirrups. ACI Structural Journal, 99(4), 530-538.

Li, V. C., Ward, R., \& Hamza, A. M. (1992). Steel and synthetic fibers as shear reinforcement. ACI Materials Journal, 89(5), 499-508.

Mansur, M. A., Ong, K. C. G., \& Paramsivam, P. (1986). Shear strength of fibrous concrete beams without stirrups. Journal of Structural Engineering ASCE, 112(9), 2066-2079.

MC2010. (2012). fib Model Code for Concrete Structures 2010, fédération internationale du béton, Lausanne, Switzerland: Ernst \& Sohn. 
Meda, A., Mostosi, S., \& Riva, P. (2014). Sehar strengthening of reinforced concrete beam with high-performance fiberreinforced cementitious composite jacketing. ACI Structural Journal, 111(5), 1059-1067.

Narayanan, R., \& Darwish, I. Y. S. (1987). Use of steel fibers as shear reinforcement. ACI Structural Journal, 84(3), 216-227.

Noghabai, K. (2000). Beams of fibrous concrete in shear and bending: Experiment and model. Journal of Structural Engineering ASCE, 126(2), 243-251.

Pan, A., \& Moehle, J. P. (1989). Lateral displacement ductility of reinforced concrete flat plates. ACI Structural Journal, 86(3), 250-258.

Park, S. H., Kim, D. J., Ryu, G. S., \& Koh, K. T. (2012). Tensile Behavior of ultra high performance hybrid fiber reinforced concrete. Cement and Concrete Composites, 34, 172-184.

Parra-Montesinos, G. J. (2006). Shear strength of beams with deformed steel fibers. Concrete International, 28(11), 57-66.
Rossi, P., Arca, A., Parant, E., \& Fakhri, P. (2005). Bending and compressive behaviors of a new cement composite. Cement and Concrete Research, 35, 27-33.

Sharma, A. K. (1986). Shear strength of steel fiber reinforced concrete beams. ACI Journal, 83(4), 624-628.

Voo, Y. L., Poon, W. K., \& Foster, S. J. (2010). Sheear strength of steel fiber-reinforced ultrahigh-performance concrete beams without stirrups. Journal of Structural Engineering ASCE, 136(11), 1393-1400.

Wafa, F. F., \& Ashour, S. A. (1992). Mechanical properties of high-strength fiber reinforced concrete. ACI Materials Journal, 89(5), 440-455.

Wille, K., Kim, D. J., \& Naaman, A. E. (2011a). Strain hardening UHP-FRC with low fiber contents. Materials and Structures, 44, 583-598.

Wille, K., Naaman, A. E., \& Parra-Montesinos, G. J. (2011b). Ultra-high performance concrete with compressive strength exceeding $150 \mathrm{MPa}(22 \mathrm{ksi})$ : A simpler way. ACI Materials Journal, 108(6), 46-54. 